\title{
Emotional Abuse Issue in Emma Donoghue's Room
}

\author{
Arilia Triyoga \\ arilia@pbi.uad.ac.id \\ English Education Department, Universitas Ahmad Dahlan, Yogyakarta, Indonesia
}

\begin{abstract}
Room is a best-seller novel written by Emma Donoghue. It tells about a mother and her son who struggle to be free from a very wicked man, Old Nick. This novel shows violence toward a woman. This paper aims to investigate emotional abuse in Emma Donoghue's Room. This research is categorized in library research, and the data are gathered mainly from the primary source, Room. The secondary sources are from journals especially discussing domestic violence and abuse toward women. Other than that, research method books are also used to support this research. The data are found through note-taking. After that, those are classified and analyzed. The finding shows that Ma's emotional abuse is in isolation and ignorance, leading her to depression and anxiety. Old Nick isolates $\mathrm{Ma}$ in a tiny room, and after $\mathrm{Ma}$ is free from Old Nick, she is ignored by some of her family. Those experiences mainly cause ma's depression and anxiety.
\end{abstract}

Keywords: Room, Emotional abuse, Isolation, Ignorance

\section{INTRODUCTION}

Emma Donoghue, born in Dublin, is an Irish writer who is an expatriate. He currently lives in Canada. She is mainly associated with Irish literature and Irish lesbian fiction because of her Irish history and higher education at University College Dublin, English Department (Bartu, 2017). Emma Donoghue's Room tells about a mother, Ma, and her son, Jack, locked up in a tiny room with a locked door and glass window on the top. They eat, sleep, cook, and clean themselves in the same room and cannot see outside the room but through the top's glass window. In that tiny room, they experience violence, but $\mathrm{Ma}$ experiences violence more than Jack. Old Nick does it. Old Nick is not a nice person; he is a possessive person then he does not want Ma to live free from him. Nick's typical violence is domestic violence because he has an intimate relationship with the victims. Physical, sexual, psychological, and financial aspects and controlling or abusive actions and behaviors may involve domestic violence (Gulati \& Kelly, 2020). Similarly, Leach et al. (2020) state that domestic and family abuse is a significant public health issue. Globally, in their lifetime, an estimated $30 \%$ of women have experimental physical and sexual intimate partner violence.

Therefore, even after traumatic events unrelated to the emotional abuse itself, emotional abuse can indirectly lead to more severe symptoms of PTSD as parents may 
have less social support to cope with the traumatic event or as a result of exposure to emotional abuse through a lack of adequate emotional control capabilities. Besides, emotionally abusive parents may also provide the child with obstructive or maladaptive perceptions of the traumatic experience that are considered to be correlated with more extreme PTSD, such as self-blame attributions, evaluations of the origin of the trauma, and attributions to the perceived dangerousness of the environment (Woodward et al., 2015; Palosaaro et al., 2016).

People can identify physical abuse easier than emotional abuse. Emotional abuse is a non-physical attitude using humiliation or fears that and is designed to control, subdue, punish or isolate another person. Children in family and other social settings, such as their education, are likely to experience emotional violence. Meanwhile, emotional neglect in family environments and by caregivers. Emotional abuse also co-occurs with other childhood maltreatment types. Emotional abuse, emotional neglect, and physical abuse tend to occur together (Brown et al., 2019; Kim et al., 2017). Emotional abuse by peers in schools has been thoroughly studied, and emotional abuse by teachers has not been sufficiently investigated (Jackson et al., 2016). While positive relationships between teacher and student contribute to students' well-being, negative aspects of these relationships can negatively affect their socio-emotional adjustment (Skalicka et al., 2015). While parental social support may safeguard against the effects of stressors (Lougheed et al., 2016)

Domestic and family abuse is a significant public health issue. Globally, in their lifetime, an estimated $30 \%$ of women have experimental physical and sexual intimate partner violence (Leach et al., 2020). Anxiety and depression, such as suicide, injury, homelessness, sexually transmitted diseases, adverse pregnancy outcomes, and alcohol abuse, are common effects of family, domestic and sexual violence (AIHW, 2017; Ayre et al., 2016; Walsh et al., 2015). Emotional abuse can include verbal assault, dominance, control, isolation, ridicule, or the use of intimate knowledge for degradation (Follingstad, Coyne \& Gambone, 2005). It is serious, and It has a huge impact on the victim's life. Being obvious or subtle to a neglected or enacted behavior forms emotional abuse (Smulens, 2010). Recent findings have shown that emotional abuse is the essential indicator of adult PTSD symptoms relative to other childhood abuse types (Taillieu et al., 2016; Vang et al., 2018).

Emotional abuse is way different from physical abuse that people can quickly identify. The victims can say that they experience mental abuse if they experience one or several 
types of mental abuse such as exploitation, ignorance, terror, isolation, and verbal abuse (Gerbarino et al., 1986). It causes severe effects, especially psychological effects. The victims suffer psychological problems. Therefore, recognizing protective factors and the analysis of their relationships linked to the particular risk leads to a better disregard of how resilience functions in each specific context, which eventually contributes to creating more successful strategies (Nearchou, 2018). Emma Donoghue's Room is interested in being analyzed in some points. Cindy (2018) discussed depression in the main characters, and Ruhfaida (2017) investigated the world's main character's curiosity. No research investigates the mental abuse in Emma Donoghue's Room. Since most people are still unaware of mental abuse, this study investigates emotional abuse as reflected in Emma Donoghue's Room.

\section{METHOD}

Mental abuse in Emma Donoghue's Room is investigated psychologically since it relates to the human mind. Then it is explained, interpreted, and evaluated from literary works (Subhan, 2015). This research is categorized into library research. The research's primary data are from Emma Donoghue's Room as the primary source of this research. The data are supported by secondary sources, journals, and books. Mental abuse toward women is categorized into a type of domestic violence. Journals discussing domestic violence and mental abuse are used to support this research. Another source is a book, especially research method books. The data are gathered from several steps. It started from library visits, source reading, note-making, data listing, and then data categorizing. After that, the data then classified based on the categorization of the mental abuse type based on the type proposed by Gerbarino (1986).

\section{RESULTS AND DISCUSSION}

Emotional abuse is an attitude designed to control other people's power. It can be subdued, punish or isolate others. In the story, there are some emotional abuse experienced that Ma faced, as told in some quotations below:

"What wakes me up is noise over and over. Ma is not in bed. There is a bit of light, and the air is still icy. I look over the edge, and she is in the middle of the floor going thump thump thump with her hand. "What did floor do?" Ma stops; she puffs out a long breath. "I need to hit something," she says, "but I do not want to break anything." (Donoghue, 2015) 
The quotation above told after Ma explained the truth for the first time to Jack. She looks stress because what she said could not be proved to Jack at that time. On the other hand, she has to tell the truth to make Jack understand if the real world is not only "Room." Without evidence, Jack thinks what Ma said is lying, but the conditions did not on Ma's side at that time. For many years Ma always told him that the world only room and outside was just fantasy, so to make Jack believe what Ma said at that time is not easy work. Ma did not know what she should do without evidence. She seemed a bit discouraged and tried to hit the floor, as told in the quotation above. This condition caused Ma's emotions disturbed, and she did anything as her impingement. She did not realize what she could be injuring herself. The isolation experienced by the victim of emotional abuse leads him/her to severe depression (Follingstad et al., 2005). Isolation aims to undermine the victim's life and identity outside the relationship and foster a sense of dependency (Karakurt \& Silver, 2013). Another quotation that showed Ma's emotional experience as seen in the story:

"I used to be scared to go to sleep, in case he came back," says ma, "but when I was asleep was the only time I was not crying, so I slept about sixteen hours a day." (Donoghue, 2015)

The quotation above told how frightened $\mathrm{Ma}$ at that time. She had become a victim of abduction by an older man where she was only 19 years old. Throughout her day in a terrible place, she has only a room and no windows at all. She has to do everything by herself and depend on the compassion of Old Nick. As a poor girl, she could not do anything besides crying for her tragic life. As told from the quotation above, to make her stop crying at that time, she slept sixteen hours a day. Asleep was the only way to help her stop crying her life. She also experienced depression at the beginning of her tragic life, as seen in the quotation below:

"I drove myself crazy looking at my watch and counting the seconds. Things spooked me, they seemed to get bigger or smaller while watching them, but they started sliding if I looked away. When he finally brought the TV, I left it on twentyfour/seven, stupid stuff, commercials for food I remembered, my mouth hurt wanting it all." (Donoghue, 2015)

The quotation above showed how depressed Ma is. She spent her day tragically, with nothing to do except counting second by second her tragic life. Her emotion disturbed, she seemed no normal anymore, it appeared when she thought that all the things around her could be changed, she looked crazy and lonely as seen in the quotation above, she left the TV on twenty-four hours a day to entertain herself. Another quotation 
that showed Ma's emotional experience when she already free and met her mother for the first time after free as seen in the story:

"Where is dad?" asks Ma. "In Canberra right now, but he is on his way," says Grandma. "There has been a lot of changes, sweetheart." "Canberra?" said Ma. "Oh honey, it is probably too much for you to take in." (Donoghue, 2015)

The quotation above described the condition of Ma's Family when she stayed in the "Room." At that moment, Ma and her mother met for the first time after kidnapped. She looked for her father, but her mother told the condition of their family. Ma's parents divorced, and her mother lives with Leo, her mother's new husband, while her father stays in Canberra. Ma was shocked, and she got an emotional attack. In-room, Ma always dreamed of being free and then spend her day with her parent, Jack, and Paul, her brother, happily, but the fact damaged it back. She should accept the bitter reality her parent have divorced. As an ordinary woman, Ma cannot do anything besides cried and sadness. She has to accept the fact. After several times got emotional attack, Ma has to felt an emotional attack again. It happened when she met her father. Ma's father seemed unable to accept Jack's presence in his daughter's life. This moment told in the quotation below:

"Ma butts in, "Dad, this is Jack." He shakes his head. He is looking at the table, and he is all sweaty on his face. "No offense." "What do you mean, no offense?' Ma's talking nearly shout. "I cannot be in the same room. It makes me shudder." "There is no it, and He is a boy; he is five years old," she roars." (Donoghue, 2015)

The quotation above showed that Ma's father could not accept Jack to his life and family. He turned his face away and did not see his grandson at all. He also said to $\mathrm{Ma}$ that if he could not be in one room with Jack, her father made Ma disappointed. All the time, Ma always imagined if she and Jack's presence could be accepted in Ma's family, and they spent their life happily. In reality, Ma has to felt disappointed anymore. What she imagined could happen. Jack could not accept her father's life. The conditions above indeed attacked Ma's emotions hardly.

\section{CONCLUSION}

Emotional abuse reflected in Emma Donoghue's Room is mainly in the type of isolation and ignorance. The victim of emotional abuse in the novel is Ma. Ma experiences Emotional abuse from Old Nick, the older adult who kidnapped her. Old Nick kidnapped $\mathrm{Ma}$ and isolated her in a tiny room. After she is free from Old Nick, Ma gets another problem. She needs to face her family, whom some of them reject Ma's son. This isolation 
and ignorance lead Ma to severe depression and anxiety. Moreover, mental abuse is a severe problem. The researcher suggests for other researchers to dig more into this issue. Hopefully, there will be more studies about mental abuse in the educational field.

\section{ACKNOWLEDGEMENTS}

This research is part of collaborative research in the English Education Department Universitas Ahmad Dahlan. The writer thanks Novela Saputri, who helped in conducting this research.

\section{REFERENCES}

AIHW. (2017). Hospitalized assault injuries among women and girls, Cat.no. INJCAT 184. Canberra, Australia: AIHW (Australian Institute of Health \& Welfare).

Ayre, J., Lum On M., Webster K., Gourley M., \& Moon L. (2016). Examination of the burden of disease of intimate partner violence (ANROWS against women in 2011: final report Horizons, 06/2016). Sydney: ANROWS.

Bartu, C. M. (2017). The Fairy Godmother is In Love With The Princess: Lesbian Desire in The Rewritten Fairy Tales Of Cemre Mimoza Bartu This article is a revised version of a part of the second chapter of my Master Thesis entitled " Disenchanting Patriarchal Fairy Tales thr. DTCF Dergisi, 1, 383-406. https://doi.org/10.1501/Dtcfder

Brown, S. M., Rienks, S., McCrae, J. S., \& Watamura, S. E. (2019). The co-occurrence of adverse childhood experiences among children investigated for child maltreatment: A latent class analysis. Child Abuse \& Neglect, 87, 18-27

Cindy, A. (2018). The Main character's Depression As Reflected in Emma Donoghue's Room: A Psychological Approach. Unpublished S1 Thesis. English Education Department of Faculty of Teacher Training and Education: Universitas Ahmad Dahlan Yogyakarta.

Flury, M., Nyberg, E., \& Riecher-Rössler, A. (2010). Domestic Violence Against Women: Definitions, Epidemiology, Risk Factors and Consequences. Swiss Medical Weekly, 4-6.

Follingstad, Diane R., Coyne., S., \& Gambone, L. (2005). A Representative Measure of Psychological Aggression and Its Severity. Violence and Victims. 20 (1), DOI: 10.1891/vivi.2005.20.1.25

Garbarino J., Guttmann, E., \& Seeley, J.W. (1986). The Psychologically Battered Child. San Francisco: Jossey-Bass.

Gulati, G., \& Kelly, B. D. (2020). Domestic violence against women and the COVID-19 pandemic: What is the role of psychiatry? International Journal of Law and Psychiatry, 71 (May), 101594. https://doi.org/10.1016/j.ijlp.2020.101594

Kim, K., Mennen, F. E., \& Trickett, P. K. (2017). Patterns and correlates of co-occurrence among multiple types of child maltreatment. Child \& Family Social Work, 22 (1), 492-502

Lougheed, J. P., Koval, P., \& Hollenstein, T. (2016). Sharing the burden: The interpersonal regulation of emotional arousal in mother-daughter dyads. Emotion, 16(1), 83-93.

Leach, M. J., Lorenzon, H., \& Nidich, S. (2020). Transcendental Meditation for women affected by domestic violence: Study protocol of a pilot randomised, controlled trial. Integrative Medicine Research, 9 (4), 100432. https://doi.org/10.1016/j.imr.2020.100432

Nearchou, F. (2018). Resilience following emotional abuse by teachers: Insights from a crosssectional study with Greek students. Child Abuse and Neglect, 78 (May 2017), 96-106. 
https://doi.org/10.1016/j.chiabu.2017.10.012

Ruhfaida, A. (2017). The Main Character's Curiosity Toward the World As Reflected in Room by Emma Donoghue: An Objective Approach.Unpublished S1 Thesis. English Education Department of Faculty of Teacher Training and Education: Universitas Ahmad Dahlan Yogyakarta.

Palosaari, E., Punamaki, R. L., Peltonen, K., Diab, M., \& Qouta, S. R. (2016). Negative social relationships predict posttraumatic stress symptoms among war-affected children via posttraumatic cognitions. Journal of Abnormal Child Psychology, 44(5), 845-857.

Skalicka, V., Stenseng, F., \& Wichstrom, L. (2015). Reciprocal relations between student-teacher conflict, children's social skills and externalizing behavior: A threewave longitudinal study from preschool to third grade. International Journal of Behavioral Development, 39, 413425. http://dx.doi.org/10.1177/ 0165025415584187.

Smullens, S. (2010). The codification and treatment of emotional abuse in structured group therapy. International Journal of Group Psychotherapy, 60(1), 111-130.

Subhan, B. 2015. A Guide to Literary Criticism. Yogyakarta: Debut Press.

Taillieu, T. L., Brownridge, D. A., Sareen, J., \& Afifi, T. O. (2016). Childhood emotional maltreatment and mental disorders: Results from a nationally representative adult sample from the United States. Child Abuse \& Neglect, 59, 1-12.

Vang, M. L., Shevlin, M., Karatzias, T., Fyvie, C., \& Hyland, P. (2018). Dissociation fully mediates the relationship between childhood sexual and emotional abuse and DSM-5 PTSD in a sample of treatment-seeking adults. European Journal of Trauma \& Dissociation, (4), 173-178.

Walsh, J., Spangaro, J., \& Soldatic, K. (2015) Global understandings of domestik violence. Nurs Health Sci, 17:1-4.

Woodward, M. J., Eddinger, J., Henschel, A. V., Dodson, T. S., Tran, H. N., \& Beck, J. G. (2015). Social support, posttraumatic cognitions, and PTSD: The influence of family, friends, and a close other in an interpersonal and non-interpersonal trauma group. Journal of Anxiety Disorders, 35, 60-67. 